\title{
CONSERVATIVE MANAGEMENT, A PREFERRED FIRST LINE METHOD FOR TREATMENT OF EPISTAXIS.
}

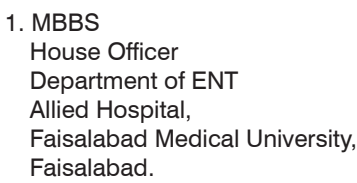

Correspondence Address: Dr. Muhammad Awais Javed Department of ENT Allied Hospital,

Faisalabad Medical University, Faisalabad.

awaisdr3@yahoo.com

Article received on: 05/07/2019

Accepted for publication: $15 / 09 / 2019$

\begin{abstract}
Muhammad Awais Javed
ABSTRACT: Epistaxis is defined as hemorrhage from nose where source of bleeding is inside the nose. There are many factors which can precipitate epistaxis. A number of treatment modalities are used for its treatment, conservative measures and nasal packing being the commonest method of treatment. Conservative method is an effective method of treatment and avoids potential complications of nasal packing. Objectives: To assess efficacy of conservative mode of treatment for epistaxis. Study Design: Prospective study. Settings: Department of Otorhinolaryngology, E.N.T. Unit-I, Allied Hospital/ Faisalabad Medical University, Faisalabad. Period: Three months i.e. from 16-10-2018 to 15-01-2019. Sample Size: 60. Material and Method: Procedure: 60 patients were enrolled according to inclusive and exclusive criteria. Conservative measures were applied to patients including cold water gargles, nasal pinching and Trotter's method. Patients were observed for control of epistaxis and number of patients noted in whom conservative measures were not successful and nasal packing was done. No patient among the sample needed the surgical intervention due to failed conservative measures or nasal packing. Frequency and percentage calculated for data and chi-square test applied and level of $<0.05$ taken significant. Results: 60 patients enrolled with age range from 5-75 years and mean age as 39.53 years. Out of 60 patients, 38 were male and 22 were females. Out of 60 patients, 42 patients (70\%) were treated successfully using conservative measures and 18 patients (30\%) were treated with nasal packing. Conclusion: Based upon results of this study, it is concluded that conservative method of treatment of epistaxis is an effective and safe method and avoids potential complications which can occur due to nasal packing.
\end{abstract}

Key words: $\quad$ Epistaxis, Conservative, Nasal Packing.

Article Citation: Javed MA. Conservative management, a preferred first line method for treatment of epistaxis. Professional Med J 2019; 26(11):1998-2002. DOI: 10.29309/TPMJ/2019.26.11.3914

\section{INTRODUCTION}

Epistaxis is defined as hemorrhage from inside the nose. ${ }^{1}$ Most common artery involved is sphenopalatine artery. It has two varieties, anterior epistaxis, when source of bleeding is in anterior part of nose, the most common source is Little's area (in $90 \%$ of cases) ${ }^{2,3}$, and posterior epistaxis, in which source of bleeding is in posterior part of nose and blood flows posteriorly in throat. ${ }^{4}$ Epistaxis is common emergency being encountered in in E.N.T units that about $60 \%$ of population has to suffer from epistaxis once in a life ${ }^{5}$ and at least $10 \%$ of them ever had been entertained with medical treatment for epistaxis. ${ }^{6}$ In one study in United States, it has been demonstrated that nearly $5 \%$ of patients with epistaxis needed hospitalization admission. ${ }^{7,8}$
The incidence of episodes of epistaxis differs with the age. Researches show bimodal distribution with peak values in children and adult age groups. ${ }^{9}$ Nose has rich vascular supply from internal carotid and external carotid arteries. ${ }^{10}$ That is why bleeding is quite common from nose. Mostly anterior epistaxis is encountered which concludes $90 \%$ of cases while $10 \%$ of cases are of posterior epistaxis. ${ }^{11}$ Common causes of epistaxis include trauma, structural and environmental factors, metabolic factors, tumors, blood diathesis, inflammatory causes and drugs. ${ }^{12}$ In drugs, anticoagulants are risk factor for epistaxis. ${ }^{13,14,15,16}$ About $24-33 \%$ of patients admitted in hospital for treatment of epistaxis give the history of anticoagulant therapy. ${ }^{17}$ Similarly, patients with bleeding diathesis come 
with recurrent episodes of epistaxis. Different studies in this regard have shown that clotting profile should be performed in patients with suspicion of clotting disorder ${ }^{18}$, especially those who come with recurrent epistaxis. Environment and weather also become the important factor as several studies show that episodes of epistaxis are increased in cold environment and cold weather. ${ }^{19}$ Hypertension is also an important factor in cases of epistaxis especially in people who come in hospital settings and have fear of it. $^{20}$ In all patients who come with high blood pressure and epistaxis, blood pressure should be controlled first. ${ }^{21,22}$ Among all these causes, common cause is trauma, nose pricking being the most common traumatic cause ${ }^{23}$, especially in children. Treatment options include conservative measures and specific measures. Conservative measures include cold water gargles, pinching of nose $^{24}$ and Trotter's method. Specific measures include anterior nasal packing, posterior nasal packing, endoscopic cauterization, vessel ligation and TESPAL. TESPAL stands for "trans-nasal endoscopic sphenopalatine artery ligation". This procedure is done with endoscopic technique, in which sphenopalatine artery is coagulated or clipped with help of bipolar diathermy. Although its success rate is high ${ }^{25}$, but this technique is seldom used as use of cautery increases the risk of septal perforation especially if it is done on both sides. ${ }^{26}$ Of all these modalities, commonly used are conservative measures and nasal packing. Nasal packing is considered as first line treatment option in many centers, however nasal packing is associated with many complications like pain, trauma, nasal infection, necrosis of nasal mucosa and posterior dislocation. In some countries, topical antiseptic cream or petroleum jelly are used to treat recurrent epistaxis but its efficacy is not fully established. ${ }^{27}$ In our part of world, study is lacking which can compare conservative treatment, which is associated with no potential side effects, to nasal packing which can be hazardous. So this study is conducted to look for efficacy of conservative mode of treatment of epistaxis as first line method of treatment.

\section{OBJECTIVE}

To assess efficacy of conservative mode of treatment for epistaxis.

\section{MATERIAL AND METHOD}

\section{Study Design}

Prospective study.

\section{Settings}

Department of Otorhinolaryngology, E.N.T. Unit-I, Allied Hospital/ Faisalabad Medical University, Faisalabad.

\section{Duration}

Three months i.e. from 16-10-2018 to 15-01-2019.

\section{Sample Size}

60

\section{Sampling Technique}

Non-probable consecutive sampling.

\section{Inclusion Criteria}

Patients presenting in E.N.T. Unit-I, Allied Hospital, Faisalabad for treatment of epistaxis.

\section{Exclusion Criteria}

Patients presented with traumatic basal fractures and patients with congenital bleeding diathesis were excluded from study.

\section{Procedure}

60 patients were enrolled according to inclusive and exclusive criteria. Conservative measures were applied to patients including cold water gargles, nasal pinching and Trotter's method. Patients were observed for control of epistaxis and number of patients noted in whom conservative measures were not successful and nasal packing was done. No patient among the sample needed the surgical intervention due to failed conservative measures or nasal packing.

\section{Statistical Analysis}

Obtained data observed and categorized according to gender and age groups. Frequency and percentage calculated for data and chisquare test applied and level of $<0.05$ taken significant. 


\section{RESULTS}

60 patients enrolled with age range from 5-75 years and mean age as 39.53 years. Out of 60 patients, 38 were male and 22 were females. Patients were stratified in group I to group III as group I (less than 25 years), group II (25-50 years) and group III (more than 50 years). Patients were stratified to group to gender distribution.

Out of 60 patients, 42 patients (70\%) were treated successfully using conservative measures and 18 patients $(30 \%)$ were treated with nasal packing.

Patient's group to gender and treatment modality distribution is done. (Table-III).

Statistical analysis is applied for using chi-square test and found that patients of all three age groups can be safely treated with conservative measures as first line modality for either gender.

\section{DISCUSSION}

Epistaxis is bleeding from nose and is due to various causes. The cases of epistaxis are seen commonly in males than in females. ${ }^{28}$ Epistaxis is found prevalent in younger age group (less than 10 years) and old age group (age more than 60 years ${ }^{29}$, with males having relatively more history of episodes of epistaxis as compared to females (ratio of 1.6) ${ }^{30}$ Selection for treatment modality to treat epistaxis is based upon clinical condition of the patient, efficacy of treatment modality, rate of complication and cost effectiveness related to treatment option. Conservative measures and nasal packing are two treatment methods which fulfilled above mentioned qualities and among the two, conservative measures carry least complication rate and high efficacy. According to a study, conservative measures were successful in treating epistaxis in which $81.66 \%$ were treated successfully. ${ }^{31}$ Another study showed similar results..$^{32}$ Our study shows consistent results with previously done studies and showing $70 \%$ of patients were successfully treated for epistaxis by conservative measures and is equally effective in all age groups and in either gender.

\section{CONCLUSION}

Based upon results of this study, it is concluded that conservative method of treatment of epistaxis is an effective and safe method. It avoids potential complications which can occur due to nasal packing.

\begin{tabular}{|l|c|c|c|c|}
\hline & Group I & Group II & Group III & Total \\
\hline Male & 9 & 21 & 8 & 38 \\
\hline Female & 4 & 13 & 5 & 22 \\
\hline Total & 13 & 34 & 13 & 60 \\
\hline
\end{tabular}

Table-I. Group to gender distribution

\begin{tabular}{|l|c|c|c|}
\hline & Conservative & Nasal Packing & Total \\
\hline Group I & 9 & 4 & 13 \\
\hline Group II & 26 & 8 & 34 \\
\hline Group III & 7 & 6 & 13 \\
\hline Total & 42 & 18 & 60 \\
\hline
\end{tabular}

Table-II. Patient's group to treatment modality distribution

\begin{tabular}{|l|c|c|c|c|c|c|c|c|}
\hline & \multicolumn{2}{|c|}{ Group I } & \multicolumn{2}{c|}{ Group II } & \multicolumn{2}{c|}{ Group III } & \multirow{2}{*}{ Total } \\
\cline { 2 - 8 } & Conservative & $\begin{array}{c}\text { Nasal } \\
\text { Packing }\end{array}$ & Conservative & $\begin{array}{c}\text { Nasal } \\
\text { Packing }\end{array}$ & Conservative & $\begin{array}{c}\text { Nasal } \\
\text { Packing }\end{array}$ & \\
\hline Male & 6 & 3 & 15 & 6 & 4 & 4 & 38 \\
\hline Female & 3 & 1 & 11 & 2 & 3 & 2 & 22 \\
\hline Total & 9 & 4 & 26 & 8 & 7 & 6 & \multirow{2}{*}{60} \\
\hline
\end{tabular}

Table-III. Patient's group to gender and treatment modality distribution 
Moreover the general awareness of conservative measures among the population can reduce the patient load of hospitals. So, conservative measures should be considered as preferred first line of treatment option for epistaxis.

\section{Copyright@ 15 Sep, 2019.}

\section{REFERENCES}

1. Dhingra PL, Dhingra S. Diseases of Ear, Nose and Throat-E-Book. Elsevier Health Sciences; 2014 Jun 5. 33:176.

2. Dhingra PL, Dhingra S. Diseases of Ear, Nose and Throat-E-Book. Elsevier Health Sciences; 2014 Jun 5. 33:177.

3. Douglas R, Wormald PJ. Update on epistaxis. Curr Opin Otolaryngol Head Neck Surg. 2007; 15:180-183.

4. Dhingra PL, Dhingra S. Diseases of Ear, Nose and Throat-E-Book. Elsevier Health Sciences; 2014 Jun 5. 33:178.

5. Petruson B, Rudin R. The frequency of epistaxis in a male population sample. Rhinology.1975; 13:129-133.

6. Rocky J.G., Anand R.A. Critical audit of surgical management of intractable epistaxis using sphenopalatine artery ligation/diathermy. Rhinology. 2002; 40(3):147-149.

7. Smith J, Siddiq S, Dyer C, Rainsbury J, Kim D. Epistaxis in patient taking oral anticoagulant and antiplatelet medication: Prospective cohort study. J laryngol Otol. 2011; 125:38-42.

8. Viehweg TL, Roberson JB, Hudson JW. Epistaxis: Diagnosis and treatment. J Oral Maxillofac Surg. 2006; 64:57-58.

9. Watkinson JC. Epistaxis. In: Mackey IS, Bull TR, eds. Scott Brown's otolaryngology London: Butterworths, 1997; 18/5-7.

10. Tan LK, Calhoun KH. Epistaxis. Med Clin North Am 1999; 83:43-56

11. Viehwag TL, Roberson JB, Hudson JW. Epistaxis: Diagnosis and treatment. J Oral Maxillofacial surgery. 2006; 64:511-518.

12. Walker TWM, Macfarlane TV, McGarry GW. The epidemiology and chronobiology of epistaxis: An investigation of Scottish hospital admissions 19952004. Clin Otolaryngol. 2007; 32:361-365.

13. Folz BJ, Kanne M, Werner JA: Aktuelle Aspekte Zur Epistaxis. HNO 2008; 56:1157.
14. Stadler RR, Kindler R, Holzmann D, Soyka MB. The long-term fate of epistaxis patients with exposure to antithrombotic medication. Eur Arch otorhinolaryngol. 2016; 273:2561-2567.

15. Desai NR, Krumme AA, Schneeweiss S, et al. Patterns of initiation of oral anticoagulants in patient with atrial fibrillation-quality and cost of implications. Am J med. 2014; 127:1075-1082.

16. Diamond L. Management of epistaxis, JAAPA. 2014; 27:35-39.

17. Simmen D, Heinz B: Epistaxis. Strategie. Erfah rungen der letzen 360 Hospitalisationen. Laryngo. Rhino. Otologie 1998; 77:100-6.

18. Thana MA, Nilssen EL, Hollands, etcal. Routine coagulation screening in the management of emergency admission for epistaxis- is it necessary? J laryngol otol 2000; 114:38-40.

19. Danielides V, Kontogiannis N, Bartzokas A, Lolis CJ, Skevas $A$ : The influence of meteorological factors in the frequency of epistaxis. Clin otolaryngol Allied. Sci. 2002; 27:84-8.

20. Kikidis D, Tsioufis K, Papanikolaou V, Zerva K, Hantzakos A. Is epistaxis associated with arterial hypertension? A systematic review of the literature. Eur Arch Otorhinolaryngol. 2014; 271:237-243.

21. Muiesan ML, Salvetti M, Amadoro V, et al. An update on hypertensive emergencies and urgencies. J Cardiovasc Med. 2015; 16:372-382.

22. Henny-Fullin K, Buess D, Handschin A, Leuppi J, Dieterle T. Hypertensive Krise. Ther umsch. 2015; 72:405-411.

23. Morgan DJ, Kellerman R: Epistaxis: Evaluation and treatment. Primary care 2014; 41:63-73

24. Bequignon E, Verillaud B, Robard I, et al. Guidelines of the French society of otorhinolaryngology (SFORL) First-line treatment of epistaxis in adults. Eur Ann Otorhinolaryngol Head Neck Dis. 2017; 134:185-189.

25. O'Flynn PE, Shadaba A. Management of posterior epistaxis by endoscopic clipping of the sphenopalatine artery. Clin otolaryngol 2000; 25:3747 .

26. Pond F. Sizeland A. Epistaxis strategies for management: Aust Fam Physician. 2000; 29:933-8.

27. Bruton M, Doree C. Interventions for recurrent idiopathic epistaxis (nose bleeds) in children. Cochrane Library. Issue 1.Oxford: update software, 2004. 
28. Pollice PA, Yodger MG. Epistaxis: A retrospective review of hospitalized patients. Otolaryngol Head Neck Surg.1997; 117:49-53.

29. D.J.Pallin, Y.M. Chng, M.P. Mckay, J.A. Emond, A.J. peletier and C.A. Camargo Jr., "Epidemiology of epistaxis in US emergency departments, 1992 to 2001", Annals of Emergency Medicine, vol.46,no.1,pp.77-81,2005.
30. C.L.Huang and C.H.Shu, "Epistaxis: A review of hospitalized patients", Chinese Medical Journal, vol.65,no.2, pp.74-78,2002.

31. Arshad M, Ahmad Z, Liaqat A. Epistaxis: An experience with over 100 cases. Rawal Medical. 2007; 32(2):142145.

32. Phillip AP, Milton GY. Epistaxis: A retrospective review of hospitalized patients. AJO Head neck surgery. 1997:117(1):49-53.

\begin{tabular}{|c|c|c|c|}
\hline \multicolumn{4}{|c|}{ AUTHORSHIP AND CONTRIBUTION DECLARATION } \\
\hline Sr. \# & Author(s) Full Name & \multicolumn{1}{c|}{ Contribution to the paper } & Author(s) Signature \\
\hline 1 & Muhammad Awais Javed & $\begin{array}{l}\text { Principal Author and } \\
\text { Investigator }\end{array}$ & m. Aiqued \\
\hline
\end{tabular}

